\title{
Cross-Cultural Literary Translation Studies - In the Translation of Works of Mo Yan, For Example
}

\author{
Zheng chunyan
}

\section{Zhengzhou shu qing medical college Henan 450000}

Key words: cross-cultural; Literary translation; Mo yan

\begin{abstract}
Literary translation is essentially different between different language types, cross-domain interpretation of the national culture, Mo yan depends largely on the Nobel Prize for literature achievements acquired excellent translators of their spiritual kernel canonical works and creation, the work of nationalism and cosmopolitanism tension spare no effort to show. Literature of cross-cultural translation needs not only a good command of Chinese language and culture connotation, also requires translators have high level of foreign language writing and literary creation. Cross-cultural literary translation in China, therefore, the improvement of the road to strengthen exchanges and cooperation with Chinese and foreign literature translation, emphasis on Chinese translators and sinologists have complementary advantages, also want to pay attention to cultivating their own literature cross-cultural translation talents, thus promote cross-cultural literary translation in China in the world.
\end{abstract}

\section{Introduction}

Though, Mo yan in the Nobel Prize for literature in 2012 achievement will on basin in world literature of Chinese literature, but the weak cross-cultural translation literature still makes Chinese literature in the edge and weak position. Successful translation in addition to reproduce the original work to complete the kernel spirit of classic, shall also be rich literary creativity and cosmopolitan tension, cross-cultural interpretation of Chinese literature has become urgent problems translation. In Mo yan's literary works under the background of cross-cultural translation, for example, to explore the literature translation quality requirements and improvement strategy has important practical significance.

\section{Mo yan cross-cultural interpretation of literary translation}

The 2012 Nobel Prize in literature to Mo yan's works to the Chinese people and the world in front, winning the reason is that Mo yan's works will be fantastic realism combined with historical and contemporary folk stories For the Swedish academy, in addition to tension, Mo yan's own literature reflects the cross-cultural interpretation of translation is also affect their important influence factors of the decision. The best translation for the works of cross-cultural interpretation is the English version of Guo haowen and Anna Chen swe translation, two people is almost in another language, tells the story of the literature, Mo yan, the loyalty to the original, recreating, Mo yan style RouRu technical processing technique at the same time, the work of some words and sentences, paragraphs and even local characteristic culture and customs of the phenomenon to do cross-cultural interpretation. Finally present translation from the original lengthy complex and has a distinct characteristic of beautiful elegance, readable. This is undoubtedly to Mo yan's literary works on 
"classic" and "creation". Thus we think of academician of Swedish academy malmqvist has failed to win the Nobel Prize for literature of China in the 1980 s due to the lack of a good translation of rhetoric, despite the comments caused a domestic literary uproar, but today it seems this is the point of speech. Writer's literature quality even if is the primary factor in the decision can be awarded the Nobel Prize for literature, but under the condition of the cultural differences are difficult to overstep directly, to judge from reading the translation directly in terms of cross-cultural interpretation performance is particularly important.

Mo yan won the Nobel Prize for literature is no accident, but the result of the combined action of many factors, the quality of the work itself nominated for the Nobel Prize for literature has laid a foundation of literary criticism of his work and research caused the international socialism in the literary world, and its English translation and swe translation makes the Swedish academy further reading and research works are possible Mo yan, therefore, the success of the literature on the Nobel literature prize with the translation of cross-cultural interpretation are inseparable, and the translator's choice of translation objects on the one hand, stems from the translator itself literary aesthetic feelings, on the other hand depends on the tension of literature itself. Obviously, Mo yan's literary nationalism and cosmopolitanism tension become translators focus on the root of their works 。 Guo haowen once said, in the early $1990 \mathrm{~s}$ was Mo yan's red sorghum, the narrative of his work because of the wide vision of world literature become a unique cultural symbol. Mo yan's literary works is not designed for the translator to write, but the author will generally face the world and is undergoing some common problems into the story of hometown in gaomi county, through Chinese narrative and the unique Angle of view to this kind of nationalism and Chinese history tension stretched. This greatly improve the translatability of literary worksIn addition, in mo yan's works we can vaguely see the shadow of the western literature, mo yan is not deny that he has no implicitly pointed out his literary creation influenced by western literary modernism and the influence of postmodernism, William Faulkner, Garcia marquez two literary master important inspiration for his creation. Without Guo haowen and Anna Chen, cross-cultural interpretation of the translation, mo yan's literary works have Swedish academy common must clearly is unlikely.

\section{Mo yan's literary translators}

Literature in what form, what kind of presents in front of the international literary connotation fundamentally largely depends on the translator's quality. Translator only to have the strong interest on Chinese culture, profound strength and strong emotion consensus can truly will present China's culture as part of the professional consciousness, to translate the Chinese culture and spare no effort to pour. Guo haowen, Anna Chen was literature at home and abroad and the common recognition of mo yan works best translator, is immersed in Chinese culture for a long time, they truly represent the spirit of the original kernel content and creation, as Howard goldblatt said, "I really like mo yan's literary works, did not translate them and enjoy". This consciousness of cross-cultural interpretation of literary works reflect the translator for Chinese cultural elements of strong feelings.

In fact, China's famous writer thering is no lack of mastering a foreign language, but when they in the translation work is difficult to achieve the desired effect, zhang ailing and bai xianyong is the most typical exampleAs a result, Chinese people no matter how much foreign language level is high, its translation effect is always unsatisfactory This is because the application level of the language of the translator is not decided the only elements that literary translation, the translator accurate interpretation of the two cultures and cross-domain interpretation is more important. Therefore, the Chinese literature must be proficient in Chinese, and have high level of foreign language writing translators to translate just easier to obtain international recognition.. Guo haowen 
can vividly express mo yan in the kernel spirit of literature lies in its in-depth study and research Chinese years later can roam between language and culture both in English and Chinese, this alone can accurately grasp the skills of the work towards language is irreplaceable.

In China's literary translation, it is difficult to language for translation, but the rich Chinese culture connotation cross-cultural interpretation of the text. Literary works in the spirit of the main point lies in the profound connotation of national culture, which determines the translator words simply by surface conversion or language of translation is difficult to grasp the essence of literature 。Guo haowen, wen-na Chen is indispensable to the successful translation of literary works on mo yan their profound literary accomplishment, good translator to be sharp and unique literary aesthetic Angle of view to choose excellent translation object, rather than blindly cater to operation of the commercial market demand. Guo haowen choice of contemporary literary works may do not have to dig deeper into the value of the translation, the sharp and unique literary perceptual is derived from the translator to profound attainments of Chinese culture.

Cultural context decided the difference of the cultural elements of a language is very difficult to find in another language completely equivalent part, which requires the translator to general cultural connotation of two languages on the basis of personal literary creativity, and then realize the transformation of literary spirit Will be accompanied by a large number of figures of speech in the process of literary creation, imagery expression, the use of dialect culture particularity, the translators full expression in terms of the original thought is a huge challenge.. Simple literal translation to the original spirit of strangled, only to give full play to the translator's literary creativity makes the translation of the original. Mo yan literary works often use local ethnic characteristics of the rhetoric skills, in order to achieve local dismantling of macro history, or reality. Guo haowen regards translation as a re-creation of original, mobilize their own interpreted literary creation experience and emotion to the original, so clever to handle such translation problems.

\section{Cross-cultural improvement strategy of literary translation}

Mo yan in the success of the Nobel literature prize is of tremendous progress in cross-cultural literary translation in China, however, the current talent training mechanism in translation and literary translation of cross-cultural interpretation was still behind the international advanced level. Only strengthen the cooperation and exchanges of Chinese and foreign literature translation, fully draw lessons from foreign successful experience of talent education, sustainable development environment for domestic the growing up of the translator to effectively reverse the present state of the overall level of the literary translation lag From the perspective of the successful translation of the current domestic literature, the Sinologist culture to the world of Chinese literature is still the main bear. This is because the Sinologist translation way more in line with the aesthetic habit of western literature river basin, the grasp of subtle changes in Chinese more aesthetic features.. Therefore, our country should set up corresponding strong incentives, attract foreign Sinologist committed to the translation studies of China's outstanding literary works, thus lay a foundation for our country outstanding translation talents cultivation, this to promote our country culture prosperity plays an important role in the field of world literature.

Overseas Sinologist is able to accurately grasp the foreign literature in aesthetic thinking and reading habits, but for China's traditional culture and literary thinking paradigm of the understanding of the kernel unavoidably exist deviation, on this basis, the translator's native Chinese literature culture advantage integration into cross-cultural literary translation are very necessary. In mo yan's literary works good translator Anna Chen, for example, she is a very good Sinologist, proficient in Chinese language and culture in the Swedish language subtle 
transformation, her husband is a Chinese poet, in their work on the complementary advantages make cross-cultural literary translation can be integrated into the great spirit of Chinese culture, and to avoid foreign language translation of hard and ambiguity. Again, such as, Howard goldblatt combined with China's wife li-chun Lin is a typical example. Cross-cultural translation of Chinese literature, therefore, to develop the Sinologist combines with Chinese translators, thus the problems existing in the one-way translation.

Although Chinese translators alone is difficult to do the right things translated literary works across cultures, but promote the backbone of Chinese literature to the world should still give priority to with Chinese translator. Therefore, through various channels to establish excellent domestic long-term cultivation mechanism is crucial to the translator. First of all, to cultivate good Chinese translator to create a good academic atmosphere and soil environment. On the one hand, to vigorously promote outstanding literary translator's status and treatment, attract both literature and culture and advanced foreign language level of outstanding talent in literature of cross-cultural translation career; On the other hand to set up the translation from the perspective of national qualification and qualification certificate exam, in attracting talent quantity at the same time grasp the quality levels, improve the high barriers to entry of literary translation. Second, domestic and foreign readers in the cultivation of excellent translators to demand and combine western thinking inertia, guide the Chinese translator from the perspective of foreign literature and culture paradigm thinking of the Chinese literature of cross-cultural translation mode.

\section{Conclusion:}

To truly realize the cultural prosperity of Chinese literature in world literature basin is a long process, for literature communication window to promote at home and abroad of cross-cultural understanding is an important task of literary translation in our country at present Our country has already a long time of literary implicitness decided the cross-cultural translation of literary works not only requires advanced language skills and writing level, more in need of a translator has the profound Chinese culture. Mo yan achievements fully illustrates the Nobel Prize for literature on its success of cross-cultural translation, we should seize the opportunity, draw lessons from the literature translation experience, efforts to promote Chinese literature in the world.

\section{Reference:}

[1] Xu Jun, Mo yan. About literature and literature translation - mo yan interviews [J]. Foreign language teaching and research,2015 (04).

[2] Ding Xuhui. "Killing" or "rebirth" : mo yan or revelation of the Nobel Prize for literature in Chinese literature translation [J]. Journal of southwest university for nationalities (humanities and social science edition),2013 (08)

[3] Cai Hua, Bian Yuhan . Ge Hao Wen Ying translated from Mo fiction look at Chinese Literature Translation restated phenomenon [J]. Language education,2015 (04).

[4] Zhu Dongjiang. Look from mo yan award-winning Chinese literary translation [J]. Literature education (Part 1) , 2015 (01)

[5] Chen Wei. I have seen of mo yan's Nobel Prize for literature and literary translation [J]. Journal of changchun college of education,2013 (16) 